\title{
HUBUNGAN ANTARA USIA MENARCHE DENGAN USIA MENOPAUSE PADA WANITA DI KECAMATAN KAKAS SULAWESI UTARA TAHUN 2014
}

\author{
${ }^{1}$ Mutiara Aprilia Senolinggi \\ ${ }^{2}$ Maya Mewengkang \\ ${ }^{2}$ John Wantania
}

\author{
${ }^{1}$ Kandidat Skripsi Fakultas Kedokteran Universitas Sam Ratulangi Manado \\ ${ }^{2}$ Bagian Obstetri dan Ginekologi Fakultas Kedokteran Universitas Sam Ratulangi Manado \\ Email: mutiara.senolinggi@gmail.com
}

\begin{abstract}
This stuady aimed to investigate the relationship between age of menarche to menopause in women of District Kakas of North Sulawesi in year 2014. This was a cross sectional analytic approach. Samples were taken by using purposive sampling method, in which only the samples that met the inclusion criteria that can be the subject of this study. The results showed that the value of Sig. is 0043 with a value of $\alpha=0.05$ so it could be concluded that the Sig. $<0.05$, then Ho is rejected and Ha accepted. It is claimed that there is a relationship between age of menarche to menopause. Correlation value (R) is 0.274 can be interpreted that the relationship between age of menarche to menopause age in the weak category because the value of the correlation $<0.5$. Regression models obtained $\mathrm{Y}=58.364$ to $0.879 \times(y=$ age of menopause, $\mathrm{x}=$ age of menarche). Conclusion: There was a relationship between the ages of menarche to the age of menopause in women. The earlier menarche occurs, the slower the menopause arises. Conversely, the slower the menarche occurs sooner menopause arises.
\end{abstract}

Keywords: age, menarche, menopause

\begin{abstract}
Abstrak: Penelitian ini bertujuan untuk mengetahui hubungan antara usia menarche dengan usia menopause pada wanita di Kecamatan Kakas Sulawesi Utara tahun 2014. Penelitian ini bersifat analitik dengan pendekatan cross sectional. Sampel diambil menggunakan metode purposive sampling, dimana hanya sampel yang memenuhi kriteria inklusi yang dapat menjadi subyek penelitian ini. Hasil penelitian menunjukkan bahwa nilai Sig. adalah 0.043 dengan nilai $\alpha=0,05$ sehingga dapat disimpulkan bahwa Sig. $<0,05$ maka Ho ditolak dan Ha diterima. Hal ini menyatakan bahwa ada hubungan antara usia menarche dengan usia menopause. Nilai korelasi (R) adalah 0,274 dapat diinterpretasikan bahwa hubungan antara usia menarche dengan usia menopause ada di kategori lemah karena nilai korelasi $<0,5$. Model regresi yang diperoleh $\mathrm{Y}=58,364-0,879 \mathrm{X}(\mathrm{y}=$ usia menopause, $\mathrm{x}=$ usia menarche)

Simpulan: Terdapat hubungan antara usia menarche dengan usia menopause pada wanita. Makin dini menarche terjadi, makin lambat menopause timbul dan sebaliknya.
\end{abstract}

Kata kunci : usia, menarche, menopause

Kesejahteraan yang semakin meningkat akibat kemajuan ekonomi, perbaikan lingkungan hidup dan ilmu pengetahuan, terutama karena kemajuan ilmu kedokteran, menyebabkan usia harapan hidup (life expectancy) semakin meningkat sehingga jumlah orang yang lanjut usia semakin bertambah.

Siklus kehidupan manusia normal dimulai dari bayi, kanak-kanak, remaja, dewasa sampai pada lanjut usia. Wanita melalui siklus hidup normal seiring dengan 
mengalami fase perkembangan fungsi organ reproduksi. Bertambahnya jumlah orang lanjut usia sebanding dengan bertambahnya wanita menopause. ${ }^{1}$ Seorang wanita secara normal akan mengalami menarche pada usia 11-15 tahun, dengan rata-rata menarche 13 tahun, masa reproduksi usia 15-46 tahun, dan menopause usia 50-51 tahun. Wanita Indonesia dengan wanita di Negara Barat dan Asia mengalami menopause di usia yang relatif sama yaitu sekitar 50 tahun., 3

WHO pada tahun 2007 memuat data yang menunjukkan 25 juta wanita di seluruh dunia diperkirakan mengalami menopause setiap tahunnya dimana Asia menjadi wilayah dengan jumlah wanita bergejala awal menopause tertinggi di dunia. Adapun usia harapan hidup wanita Indonesia adalah 67 tahun. $^{2}$ Populasi wanita menopause di Indonesia cenderung semakin tinggi. Data Departemen Kesehatan (Depkes) memperlihatkan bahwa wanita Indonesia mengalami menopause sebesar $7,4 \%$ dari populasi pada tahun 2000 dan diperkirakan akan meningkat menjadi $14 \%$ atau sekitar 30 juta orang pada tahun 2015. Umumnya peningkatan populasi wanita menopause akan disertai berbagai jenis permasalahan kompleks yang berdampak pada peningkatan masalah kesehatan wanita menopause tersebut. ${ }^{3}$

Rata-rata wanita yang berada di kota besar seperti Jakarta mengalami menopause pada akhir usia 40 tahun atau awal 50 tahun. Penelitian terbaru menyatakan 1 dari 16 wanita berisiko mengalami menopause dini. ${ }^{4}$ Jika menopause dini merupakan menopause yang terjadi sebelum usia 40 tahun, maka menopause yang terjadi sebelum usia 45 tahun dianggap sebagai menopause yang cepat. Dikatakan terlamba apabila menopause dialami wanita pada usia $>55$ tahun.

Banyak faktor yang berhubungan dengan usia menopause. Beberapa faktor tersebut yaitu usia pertama kali menstruasi, stress, pemakaian metode kontrasepsi, status keluarga (seperti status perkawinan, jumlah anak dan usia melahirkan anak terakhir), riwayat keluarga, pekerjaan, pendapatan, merokok, dan minum alkohol. Semakin muda seseorang mengalami haid pertama kalinya, semakin tua atau lama ia memasuki usia menopause. ${ }^{5}$

Mengingat begitu banyak faktor yang berhubungan dengan usia menopause pada seorang wanita dan terbatasnya waktu yang ada maka penulis hanya meneliti salah satu faktor yang dianggap menarik oleh peneliti yaitu mengenai hubungan antara usia menarche dengan usia menopause pada wanita di Kecamatan Kakas Sulawesi Utara tahun 2014.

\section{METODE PENELITIAN}

Penelitian ini dilakukan dengan desain observasional bersifat analitik dan menggunakan pendekatan cross sectional. Populasi dalam penelitian ini adalah seluruh wanita menopause di Kecamatan Kakas Sulawesi Utara tahun 2014. Sampel ditentukan dengan menggunakan teknik non-probability sampling sebab tidak semua wanita dalam populasi dapat menjadi sampel sehingga tidak dapat dikumpulkan secara acak. Sampel diambil dengan menggunakan metode purposive sampling, dimana hanya sampel yang memenuhi kriteria inklusi yang dapat menjadi subyek penelitian ini. ${ }^{6}$ Pengumpulan data dilakukan dengan metode wawancara berdasarkan pertanyaan-pertanyaan yang ada pada lembar kuesioner dimana jawaban juga akan diisi pada lembar tersebut.

Data yang telah diperoleh kemudian akan diolah dengan cara analisis univariat dan analisis bivariat. Analisi univariat untuk melihat distribusi frekuensi dari setiap variabel penelitian. Analisis bivariat dilakukan dengan menggunakan uji regresi linear sederhana yang berfungsi untuk mengetahui hubungan antara kedua variable penelitian dimana usia menarche merupakan variabel bebas dan usia menopause merupakan variabel terikat.

\section{HASIL PENELITIAN DAN BAHASAN}

Dari 55 responden dapat diketahui bahwa responden mengalami menarche 
terbanyak pada usia 13-14 tahun, yaitu sebanyak 23 responden (41,8\%), sedangkan yang mengalami menarche terendah pada usia $>16$ tahun ada 15 responden (27,3\%) dengan usia menarche rata-rata responden adalah 14,31 tahun $\approx 14$ atau 15 tahun. Hasil analisis univariat yang menunjukkan distribusi frekuensi usia menarche dapat dilihat bahwa usia menarche terendah 11 tahun, usia tertinggi 18 tahun, dan usia terbanyak responden mengalami menarche pada usia 14 tahun (Tabel 1)

Tabel 1.Distribusi Responden Berdasarkan Usia Menarche di Kecamatan Kakas Sulawesi Utara Tahun 2014

\begin{tabular}{ccc}
\hline Usia menarche (tahun) & $\mathrm{n}$ & $\%$ \\
\hline $11-12$ & 10 & 18,2 \\
$13-14$ & 23 & 41,8 \\
$15-16$ & 14 & 25,5 \\
$>16$ & 8 & 14,5 \\
\hline Jumlah & 55 & 100 \\
\hline
\end{tabular}

Menurut Wiknjosastro, usia remaja yang mendapat menarche bervariasi yaitu antara usia 10-16 tahun, tetapi rata-rata 12,5 tahun, antara 11-15 tahun. Dengan penggolongan : Menarche dini yaitu usia 10-11 tahun, menarche normal yaitu usia 11-15 tahun, dan menarche terlambat yaitu usia $>15$ tahun. ${ }^{5}$ Hal tersebut mendukung hasil penelitian yang dilakukan oleh peneliti di Kecamatan Kakas Sulawesi Utara tahun 2014 yang telah diuraikan sebelumnya.

Adanya variasi saat mengalami haid pertama pada seorang wanita dipengaruhi oleh banyak faktor, antara lain faktor hormonal, genetik, bentuk badan, status gizi, lingkungan, aktivitas fisik dan rangsangan psikis. ${ }^{7}$

Pada penelitian ini menopause dialami 55 responden dalam usia yang beragam yaitu pada usia $<45$ tahun sebanyak 19 responden (34,6\%), 45-55 tahun 34 responden $(61,8 \%)$ dan $>55$ tahun 2 responden (3,6\%). Hasil analisis univariat yang menunjukkan distribusi frekuensi usia menopause dapat dilihat bahwa usia menopause rata-rata responden ialah 45,78 tahun $\approx 45$ atau 46 tahun, usia menopause tertinggi 57 tahun dan usia terbanyak responden mengalami menopause pada usia 50 tahun (Tabel 2)

Tabel 2.Distribusi Responden Berdasarkan Usia Menopause di Kecamatan Kakas Sulawesi Utara Tahun 2014

\begin{tabular}{ccc}
\hline Usia menopause (tahun) & $\mathrm{n}$ & $\%$ \\
\hline$<45$ & 19 & 34,6 \\
$45-55$ & 34 & 61,8 \\
$>55$ & 2 & 3,6 \\
\hline Jumlah & 55 & 100 \\
\hline
\end{tabular}

Hasil penelitian ini sesuai dengan teori menurut Purwantyastuti mengatakan bahwa umumnya wanita Indonesia mengalami menopause di usia 45-55 tahun, tetapi ada beberapa wanita yang mengalami menstruasi terakhir sebelum umur 45 tahun, ada pula wanita yang sesudah berumur 57 tahun baru mendapatkan menstruasi terakhir. ${ }^{4}$

Adanya beberapa faktor yang mempengaruhi usia menopause menyebabkan perbedaan saat terjadinya menopause antara wanita yang satu dengan wanita lainnya. Faktor-faktor tersebut antara lain usia saat haid pertama (menarche), beban pekerjaan, status perkawinan, jumlah anak, usia saat melahirkan anak terakhir, penggunaan kontrasepsi, kebiasaan merokok, kebiasaan mengonsumsi alkohol, serta adanya riwayat penyakit tertentu yang berhubungan dengan organ reproduksi. ${ }^{8}$

Dari 19 responden yang mengalami menopause pada usia $<45$ tahun didapatkan 2 responden (10,6\%) mengalami menarche pada usia 11-12, 7 responden (36,8\%) pada usia 13-14 tahun, 3 responden (15,8\%) pada usia 15-16 tahun dan 7 responden (36,8\%) pada usia $>16$ tahun. Dari 34 responden yang mengalami menopause pada usia 45-55 tahun didapatkan 8 responden $(23,5 \%)$ mengalami menarche pada usia 11-12 tahun, 16 responden (47,1\%) pada usia 13-14 tahun, 9 responden (26,5\%) pada usia 15-16 tahun 
dan 1 responden (2,9\%) pada usia $>16$ tahun. Sedangkan 2 responden (100\%) yang mengalami menopause pada usia $>55$ tahun, keduanya mengalami menarche pada usia 15-16 tahun (Tabel 3).

Tabel 3.Distribusi Responden Berdasarkan Hubungan Usia Menarche dengan Usia Menopause di Kecamatan Kakas Sulawesi Utara Tahun 2014

\begin{tabular}{ccccccccc}
\hline $\begin{array}{c}\text { Menarche } \\
\text { (tahun) }\end{array}$ & \multicolumn{9}{c}{ Menopause } & \multicolumn{3}{c}{ Total } \\
& \multicolumn{2}{c}{$<45$} & $45-55$ & \multicolumn{2}{c}{$>$} & & \\
\cline { 2 - 7 } & $\mathrm{n}$ & $\%$ & $\mathrm{n}$ & $\%$ & $\mathrm{n}$ & $\%$ & $\mathrm{n}$ & $\%$ \\
\hline $11-12$ & 2 & 10,6 & 8 & 23,5 & 0 & 0 & 10 & 18,2 \\
$13-14$ & 7 & 36,8 & 16 & 47,1 & 0 & 0 & 23 & 41,8 \\
$15-16$ & 3 & 15,8 & 9 & 26,5 & 2 & 100 & 14 & 25,5 \\
$>16$ & 7 & 36,8 & 1 & 2,9 & 0 & 0 & 8 & 14,5 \\
\hline Jumlah & 19 & 100 & 34 & 100 & 2 & 100 & 55 & 100 \\
\hline
\end{tabular}

Hubungan antara usia menarche dengan usia menopause pada wanita di Kecamatan Kakas Sulawesi Utara tahun 2014 berdasarkan hasil analisis bivariat menggunakan uji regresi linear sederhana, diketahui nilai Sig. adalah 0.043 dengan nilai $\alpha=0,05$ sehingga dapat disimpulkan bahwa Sig. < 0,05 maka Ho ditolak dan Ha diterima. Hal ini menyatakan bahwa ada hubungan antara menarche dengan menopause. Jika melihat nilai $\mathrm{R}$ yang merupakan simbol dari nilai koefisien relasi, nilai korelasi adalah 0,274 . Nilai ini dapat diinterpretasikan bahwa hubungan antara menarche dengan menopause ada di kategori lemah karena nilai korelasi 0,274 kurang dari 0,5.

Banyak faktor yang berhubungan dengan terjadinya menopause. Beberapa faktor tersebut yaitu usia pertama kali mendapat haid (menarche), stres, pemakaian metode kontrasepsi, status keluarga (seperti status perkawinan, jumlah anak dan usia saat melahirkan anak terakhir), riwayat keluarga, pekerjaan, pendapatan, merokok, dan minum alkohol. ${ }^{4}$ Selain itu, ada juga beberapa faktor lain diantaranya polusi air/udara, pengaruh toksin patogen atau radiasi, perilaku gaya hidup modern, kebiasaan diet, olahraga, pengaruh matahari, perilaku seksual, dan gangguan mental. ${ }^{8}$
Berdasarkan hasil analisis dengan menggunakan uji regresi linear sederhana diperoleh persamaan garis sebagai berikut:

$$
\mathrm{Y}=58,364-0,879 \mathrm{X}
$$

dimana $\mathrm{y}=$ usia menopause, $\mathrm{x}=$ usia menarche.

Jika $\mathrm{X}=11$, maka nilai $\mathrm{Y}=58,364$ 0,879*11 = 48,695 (49 tahun)

Jika $X=14$, maka nilai $Y=58,364$ 0,879*14 $=46,058$ (46 tahun)

Jika $X=18$, maka nilai $Y=58,364$ 0,879*18 $=42,542$ (42 tahun)

Sehingga menghasilkan sebuah garis yang menunjukkan hubungan terbalik antara usia menarche dengan usia menopause.

Semakin dini seorang wanita mengalami menarche maka semakin lambat ia mengalami menopause. Sebaliknya, semakin lambat mengalami menarche maka semakin dini mengalami menopause. Penelitian ini sesuai dengan teori Kasdu yang mengatakan bahwa ada hubungan antara usia pertama kali mendapat haid dengan usia seseorang wanita memasuki menopause. Semakin muda seseorang mengalami haid pertama kalinya, semakin tua atau lama ia memasuki usia menopause. ${ }^{4}$

Adapun pendapat lain dari Speroff dan Reitz bahwa wanita yang terlambat mendapatkan menstruasi, pada usia 16 atau 17 tahun, justru akan mengalami menopause lebih dini, sedangkan mereka yang haid lebih dini seringkali akan mengalaminya sampai pada usia mencapai 50 tahun. Ada pola keluarga yang berlaku secara umum, bagi seorang wanita yang ibu atau kakak perempuannya lebih dini mengalami menopause maka ia juga cenderung mengalami hal yang sama, begitu pula sebaliknya. ${ }^{9,10}$

\section{SIMPULAN}

Dari hasil penelitian yang telah dilakukan diperoleh bahwa:

1. Usia rata-rata responden mengalami menarche pada usia 14 atau 15 tahun, usia menarche terendah 11 tahun, usia menarche tertinggi 18 tahun, dan usia 
terbanyak responden mengalami menarche pada usia 14 tahun.

2. Usia rata-rata responden mengalami menopause pada usia 45 atau 46 tahun, dengan usia menopause tertinggi 57 tahun, dan usia terbanyak responden mengalami menopause pada usia 50 tahun.

3. Ada hubungan antara usia menarche dengan usia menopause pada wanita. Makin dini menarche terjadi, makin lambat menopause timbul. Sebaliknya, makin lambat menarche terjadi makin cepat menopause timbul.

\section{SARAN}

1. Bagi Institusi Kesehatan agar dapat menjadi sarana informasi tentang peristiwa menarche dan menopause serta kesehatan reproduksi bagi wanita khususnya pada lansia dalam penyusunan program kesehatan.

2. Bagi tenaga kesehatan agar dapat melakukan penyuluhan tentang perubahan fisik dan psikologis yang dialami wanita pada masa menopause, terutama kepada wanita yang akan memasuki masa pra-menopause sehingga mereka dapat menghadapi perubahan-perubahan yang akan terjadi.

3. Bagi peneliti selanjutnya, perlu dilakukan penelitian terhadap faktorfaktor lain yang dapat mempengaruhi terjadinya menopause.

\section{DAFTAR PUSTAKA}

1. Simanjuntak R, Erniyati. Adaptasi Psikososial Wanita Menopause Pekerja dan Bukan Pekerja di Perumnas Mandala Kecamatan Percut Sei Tuan, Deli Serang. 2007. Dibuka pada 28 Agustus 2014 dari http://repository.usu.ac.id/bitsream/123 456789/21181/1/ruf-nov20072\%20(5).pdf.
2. Syafruddin, Hamida. Kebidanan komunitas. Jakarta: EGC; 2009. h. 241.

3. Prawiroharjo S. Ilmu Kandungan. Jakarta: PT. Bina Pustaka Sarwono Prawirohardjo; 2011.

4. Nurlaila, Rahmayani. Pengaruh peran suami dan persepsi diri terhadap kesiapan psikologi dalam dalam menghadapi klimakterium di desa lampaseh kota banda aceh. Dibuka pada 11 September 2014 dari http://180.241.122.205/docjurnal/NUR LAILA-jurnal_ella.pdf

5. Rohmatika D, Sumarni, Prabandari F. Pengaruh Usia Menarche Terhadap Usia Menopause pada Wanita Menopause di Desa Jingkang Babakan Kecamatan Ajibarang Kabupaten Banyumas Tahun 2012. 2012. Dibuka pada 28 Agustus 2014 dari http://ojs.akbidylpp.ac.id/index.php/Pra da/article/download/63/61

6. Sastroasmoro S, Ismael S. Dasardasarmetodologi penelitian klinis. Edisi ke -4. Jakarta: Sagung Seto; 2011. h. 348-82.

7. Anggraini MT. Hubungan antara usia saat timbulnya menarche dengan usia saat terjadinya menopause wanita di Kecamatan Kartasura. Dibuka pada 9 Oktober 2014 dari http://jurnal.unimus.ac.id/index.php/psn 12012010/article/view/124/105

8. Prawirohardjo S. Ilmu Kandungan. Jakarta: Tridasa Printer. 2007.

9. Safitri A. Beberapa faktor yang mempengaruhi menopause pada wanita di Kelurahan Titi Papan Kota Medan Tahun 2009. Skripsi tidak diterbitkan. Medan : Universitas Sumatera Utara. 2009.

10. Ratna A, Tendean HMM, Suparman E. Hubungan menarche terhadap menopause di Kecamatan Lalabata Kabupaten Soppeng Sulawesi Selatan. Dibuka pada 29 Oktober 2014 dari http://ejournal.unsrat.ac.id/index.php/ec linic/article/view/3670/319 